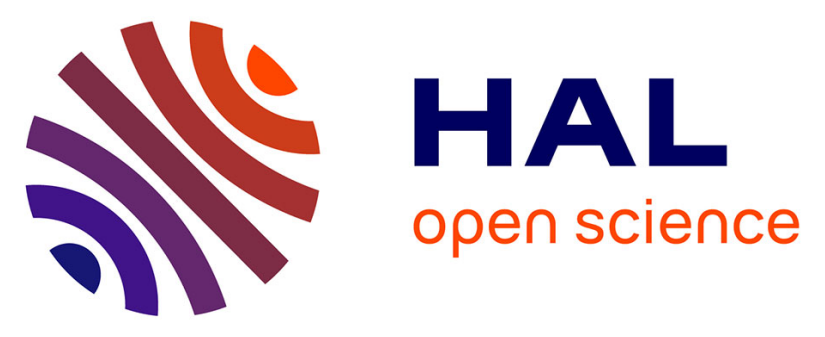

\title{
The Fermi Level as an Energy Reference in Liquid Jet X-ray Photoelectron Spectroscopy Studies of Aqueous Solutions
}

Lucía Pérez Ramírez, Anthony Boucly, Florent Saudrais, Fabrice Bournel, Jean-Jacques Gallet, Emmanuel Maisonhaute, Aleksandar R Milosavljević, Christophe Nicolas, François Rochet

\section{To cite this version:}

Lucía Pérez Ramírez, Anthony Boucly, Florent Saudrais, Fabrice Bournel, Jean-Jacques Gallet, et al.. The Fermi Level as an Energy Reference in Liquid Jet X-ray Photoelectron Spectroscopy Studies of Aqueous Solutions. Physical Chemistry Chemical Physics, 2021, 23, pp.16224-16233. 10.1039/d1cp01511g . hal-03292159

\section{HAL Id: hal-03292159 \\ https://hal.science/hal-03292159}

Submitted on 18 Nov 2021

HAL is a multi-disciplinary open access archive for the deposit and dissemination of scientific research documents, whether they are published or not. The documents may come from teaching and research institutions in France or abroad, or from public or private research centers.
L'archive ouverte pluridisciplinaire HAL, est destinée au dépôt et à la diffusion de documents scientifiques de niveau recherche, publiés ou non, émanant des établissements d'enseignement et de recherche français ou étrangers, des laboratoires publics ou privés. 


\section{ARTICLE}

\section{The Fermi Level as an Energy Reference in Liquid Jet X-ray Photoelectron Spectroscopy Studies of Aqueous Solutions}

Received 00th January 20xx Accepted 00th January 20xx

DOI: $10.1039 / \times 0 \times x 00000 x$
Lucía Pérez Ramírez $^{\mathrm{a} *}$, Anthony Boucly ${ }^{\mathrm{a}^{\dagger}}$, Florent Saudrais ${ }^{\mathrm{a}}$, Fabrice Bournel ${ }^{\mathrm{ab}}$, Jean-Jacques Gallet $^{\mathrm{ab}}$, Emmanuel Maisonhaute ${ }^{\mathrm{c}}$, Aleksandar R. Milosavljević ${ }^{\mathrm{b}}$, Christophe Nicolas ${ }^{\mathrm{b}}$ and François Rochet $^{\text {a* }}$

To advance an understanding of key electrochemical and photocatalytic processes that depend on the electronic structure of aqueous solutions, X-ray photoemission spectroscopy has become an invaluable tool, especially when practiced with liquid microjet setups. Determining vertical ionization energies referenced to the vacuum level, and binding energies referenced to the Fermi level, including the much-coveted reorganization energy of the oxidized species of a redox couple, requires that energy levels be properly defined. The present paper addresses specifically how the vacuum level "just outside the surface" can be known through the energy position of the rising edge of the secondary electrons, and how the Fermi level reference is uniquely determined via the introduction of a redox couple. Taking the case of the ferricyanide/ferrocyanide and ferric/ferrous couples, the paper also tackles issues related to the electrokinetic effects inherent to the production of a liquid jet in vacuum, which has become the standard water sample environment for photoemission experiments.

\footnotetext{
a. Sorbonne Université, CNRS, Laboratoire de Chimie Physique matière et

Rayonnement, UMR 7614, 4 place Jussieu, 75005 Paris, France

b. Synchrotron SOLEIL, L'Orme des Merisiers, Saint-Aubin - BP 4891192 Gif-sur-

Yvette CEDEX, France

c. Sorbonne Université, CNRS, Laboratoire Interfaces et Systèmes Electrochimiques,

4 place Jussieu, 75005 Paris, France.

- now at Sorbonne Université, CNRS (UMR 8234), Physicochimie des Electrolytes et Nanosystèmes Interfaciaux, 4 place Jussieu, 75252 Paris Cedex 05, France.

+ now at Paul Scherrer Institute (PSI) Forschungsstrasse 111, 5232 Villigen, Switzerland

‡ now at Institut de Biologie Intégrative de la Cellule, Saclay Campus, CEA Saclay, 91191 Gif sur Yvette Cedex, France

* Email: francois.rochet@sorbonne-universite.fr

Electronic Supplementary Information (ESI) available: thermodynamics of the metal/solution interface; comment on the calculation of the SHE absolute potential; XPS spectrometer calibration; voltammetry; potentiometry; PHREEQC calculation; C 1s spectra; jet biasing; $0.1 \mathrm{M} \mathrm{KCl}$ solution HOMO and SEEDC spectra. See DOI: $10.1039 / x 0 x x 00000 x$
} 


\section{Introduction}

Despite liquid water occupies a central role in chemistry, the determination of its electronic properties is still challenging, from both experimental and theoretical standpoints. $1,2,3,4,5,6,7,8,9-11,12$ In this context, UV or X-ray photoelectron spectroscopy (XPS) was summoned to determine the electronic structure of water. The advent of liquid microjet extreme UV photoelectron spectroscopy, more than two decades ago, enabled Winter and coworkers ${ }^{13,14,15}$ to measure directly the vertical ionization energy (IE) of liquid water HOMO $\left(1 b_{1}\right.$ level), referenced to the vacuum level (VL), "just outside the surface" of water $\left(V L^{\mathrm{S}}\right)$. Liquid jets present clear advantages over the condensation of water on a substrate in near ambient pressure (NAP) conditions, ${ }^{16,17}$ which is the experimental alternative to study liquid water with photoelectron spectroscopy: first, the surface of water is clean and radiolytic effects are minimized as the sample is continuously renewed, and second, the solutes and their concentrations can be easily changed. Importantly, solid nanoparticles can also be suspended in solutions and examined by XPS using a liquid jet setup. ${ }^{18,19,20}$ This opens interesting questions such as determining the alignment of semiconductor band edges with redox potential levels in water, especially in the context of photochemistry. ${ }^{21,22}$ In the same vein, the charge of metallic nanoparticles are imposed by the redox couple in the solution as the $\mathrm{FL}$ of the particle and the redox couple align at equilibrium, ${ }^{23}$ and XPS seems to be the ideal tool to determine changes in the electron level schemes.

Consequently, liquid jet XPS appears as a versatile and efficient tool to unravel the electronic structure of water and solutes (or suspensions) in it. However liquid jet experiments suffer from a serious issue, the question of the binding energy reference. In these experiments, $V^{S}$ is commonly determined from the known $1 b_{1}$ IE of the gas phase water molecules $\left(\mathrm{IE}_{1 \mathrm{~b}_{1}(\mathrm{~g})}=12.621 \mathrm{eV}\right)$ surrounding the jet, ${ }^{13,14,15}$ whose own vacuum level is pinned to that of liquid water (see Figure $1(\mathrm{a})$ ). Recently, positioning $\mathrm{VL}^{\mathrm{S}}$ with the gas phase $1 \mathrm{~b}_{1}$ level without careful calibrations was critically reviewed by several groups. ${ }^{24,25,26}$ As the focal point dimension of the $X$ ray beam is bigger than the jet diameter, the probed gaseous molecules do not reside "just outside" the liquid surface, and therefore one must take into consideration the contact potential difference (CPD) established between the liquid surface and the skimmer of the electron analyser (see Figure $1(b))$, that is equal to the difference in work functions. The CPD obviously impacts the measured gas phase kinetic energies. The issue is not new. Siegbahn et al. ${ }^{27}$ already proposed in 1983 a method determining an affine relationship between the measured kinetic energy of a gas phase level and its real value in the immediate vicinity of the surface of the liquid. For their part, Morgner et al. ${ }^{28}$ in 1991 proposed to align the $\mathrm{VL}^{\mathrm{S}}$ of the liquid and analyser by minimizing the width of the gas phase spectral lines. The second problem that arises in liquid jet experiments is the streaming potential $\phi_{\text {str }}$ that is due to the shearing of the double layer in the glass capillary. ${ }^{29}$ It depends on the pressure difference between the two ends of the capillary $\Delta p$ (or equivalently to the flowrate, via Poiseuille's law), the chemistry of the solution/capillary material interface, and the electrolyte concentration. ${ }^{25,30,26}$. Adding alkali halides reduces $\phi_{\text {str }}$ by increasing the conductivity of the solution (in the Helmholtz-Smoluchowski ${ }^{29}$ formula, $\phi_{\text {str }}$ is indeed inversely proportional to the solution conductivity, see below) and by decreasing the zeta potential $\zeta\left(\phi_{\text {str }} \propto \zeta\right)$. The latter effect is due to a short Debye length at the glass/solution interface (typically $1 \mathrm{~nm}$ for a $0.1 \mathrm{M} \mathrm{KCl}$ solution).

The determination of $\phi_{\text {str }}$ independently of the CPD has been, until now, impracticable in liquid jet photoemission experiments. For instance, in Kurahashi et al. ${ }^{25}$ the measured kinetic energy of gas phase $01 \mathrm{~s}$ is compared to its "true" value (in the absence of a perturbing electrostatic potential). The procedure consists in estimating the sum of $\phi_{\text {str }}$ and of the CPD for a given concentration of solutes. Therefore, the finding of an "ideal" electrolyte concentration for which the combined $\phi_{\text {str }}+$ CPD potential would be zero as in ref ${ }^{25}$ is not transferable to other experimental XPS systems with different geometries and materials used. Several groups using the gas phase $\left(\mathrm{VL}^{\mathrm{S}}\right)$ procedure have addressed the question of the combined effects of the CPD and of the streaming potential in liquid jet XPS experiments on water. The procedures of Siegbahn et al. ${ }^{27}$ and Morgner et al. ${ }^{28}$ were both used by Olivieri et al., ${ }^{24}$ and more recently the procedure of Morgner et al. ${ }^{28}$ was carried out by Perry at al.. ${ }^{31}$ The question has been reassessed by Nishitani et al. in $2020 .{ }^{26}$

In the present work, we start considering the question of using the Fermi level ( $\mathrm{FL}$ ) of the analyser as a binding energy (BE) reference as it is common practice in the XPS of (conductive) solid samples, ${ }^{32}$ instead of using the VL of liquid water. ${ }^{13,14,15,17,31}$ After briefly describing the liquid jet XPS experiment, we discuss the shape and position of the secondary electron energy distribution curve (SEEDC) and determine the work functions of the

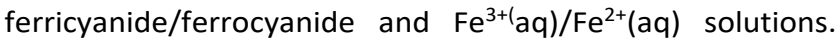
This gives us the opportunity to estimate the streaming potential. Then we focus on the measurement of binding energies (BE) referenced to $\mathrm{FL}$. In the case of the ferricyanide/ferrocyanide solution, we have obtained the $B E$ of the ferrocyanide $t_{2 g}$ level, which directly gives the reorganization energy of the oxidized species $\lambda_{\mathrm{ox}}{ }^{33}$ that is related to the electron transfer barrier energy in the MarcusHush theory. ${ }^{34}$ The vertical ionization energies of the aqueous solutions $\left(\mathrm{IE}_{1 \mathrm{~b}_{1}(\mathrm{l})}\right)$, referenced to $\mathrm{VL}^{\mathrm{S}}$ and independent of $\mathrm{FL}$, are also determined and compared with previous findings. We also show that the appearance of a surfactant like 1-butanol at the liquid/gas interface affects the $I_{E_{1} b_{1}(l)}$ of the Zobell solution. Finally, we propose ways to improve the liquid jet setups in XPS experiments by reducing the effects of the streaming potential. 


\section{Thermodynamics and Fermi level alignment}

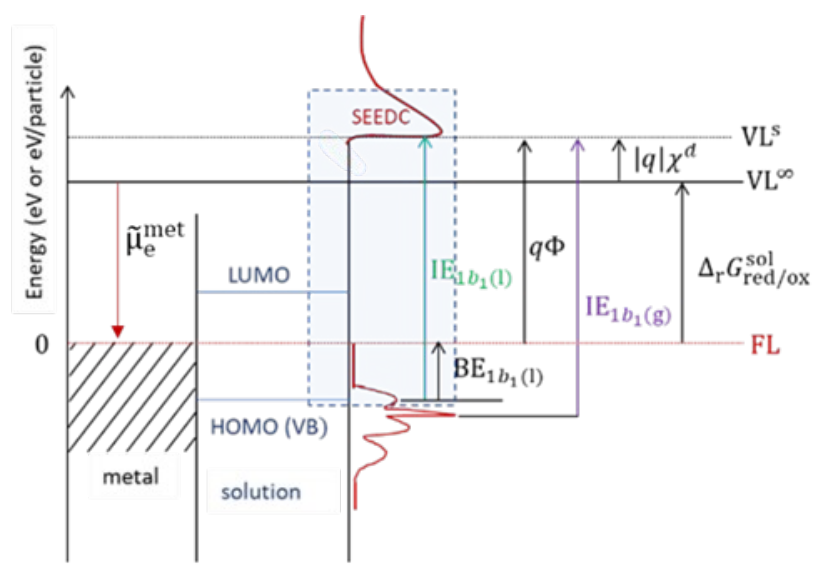

(a)

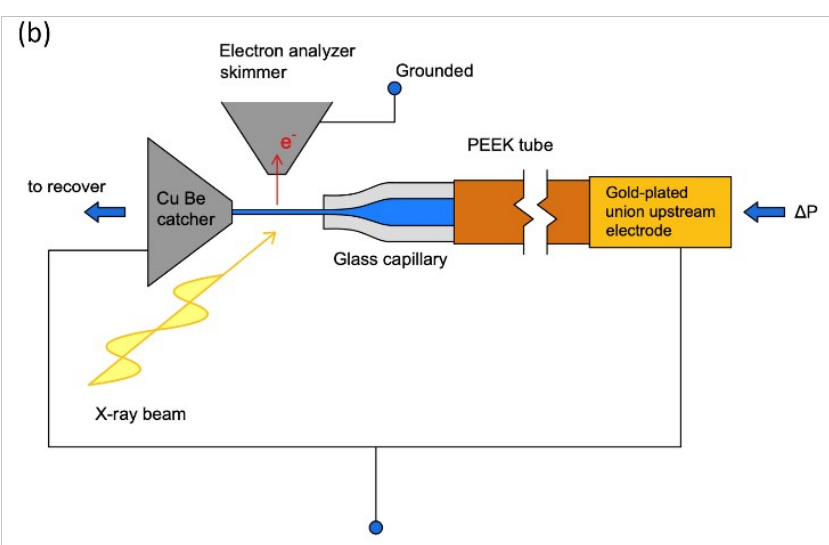

Grounded or -20V

Figure 1. (a) Energy level diagram in the absence of streaming potential. FL is the Fermi level common to the redox couple, the upstream electrode, and the analyser. $\mathrm{VL}^{\mathrm{S}}$ is the vacuum level "just outside the surface", and $\mathrm{VL}^{\infty}$ is the vacuum level at infinity. $\mathrm{q} \Phi$ is the work function of the solution and $|\mathrm{q}| \chi^{\mathrm{d}}$ the dipolar contribution to the surface potential energy. $\mathrm{BE}_{1 \mathrm{~b}_{1}(\mathrm{l})}$ and $\mathrm{IE}_{1 \mathrm{~b}_{1}(\mathrm{l})}$ are the liquid water HOMO $1 \mathrm{~b}_{1}$ binding energy (referenced to $\mathrm{FL}$ ) and the vertical ionization energy (referenced to $\mathrm{VL}^{\mathrm{S}}$ ), respectively. $\mathrm{IE}_{1 \mathrm{~b}_{1}(\mathrm{~g})}$ is the vertical ionization energy of gaseous water. $\Delta_{\mathrm{r}} \mathrm{G}_{\text {red/ox }}^{\text {sol }}$ is the (positive) Gibbs energy change (eV/particle) of the oxidation reaction red $\rightarrow \mathrm{ox}+e\left(\mathrm{at} \mathrm{VL}^{\infty}\right)$. (b) Scheme of the liquid jet setup: the upstream electrode, the glass capillary (diameter 25 or $40 \mu \mathrm{m}$, length $14 \mathrm{~mm}$ ), the downstream copperberyllium alloy catcher used to recover the solution, and the skimmer of the electron analyser. Distances are $2 \mathrm{~mm}$ between the capillary orifice and the catcher tip, 1.5 $\mathrm{mm}$ between the skimmer and the water jet. The electric diagram is also given (the analyser remains always grounded).

In XPS experiments, the FL of a metallic electrode in contact with the aqueous solution can be chosen as the zero of BEs (Figure 1(a)). The principle is the same as that adopted in our previous "static" NAP-XPS work, ${ }^{17}$ where we reported on the electronic structure of saturated alkali halide solutions condensed on a gold substrate. The $\mathrm{FL}$ is already the natural common reference level of the electrode and the analyser at thermodynamic equilibrium, when both are connected by a metallic wire. $^{32}$ What we must now focus on is the solution/electrode junction. The "FL of water" can only be defined properly if a known redox couple is present. The electrochemistry literature thoroughly addressed this question in the 1980's and it was concluded that the redox level and the Fermi level of the metal align at the junction at equilibrium, as both are electrochemical potentials. ${ }^{35,36}$ In such conditions, the valence band and core-level BEs of the solution can be referenced to a common FL. Work functions $\mathrm{q} \Phi$, i.e. the energy difference between $\mathrm{VL}^{\mathrm{S}}$ and $\mathrm{FL}$ can be also obtained by measuring the SEEDC.

With respect to our previous NAP-XPS work, ${ }^{17}$ we bring a conceptual and methodological improvement by introducing a well-defined redox couple in the solution. The redox couple enables the exchange of charge between a metallic electrode and the solution and aligns the electrochemical potentials. In its absence, the electrode is unpoised: Percival and Bard ${ }^{37}$ have shown that the open circuit potential (OCP) varies between $\sim 0 \mathrm{~V}$ for a de-aerated solution and $520 \mathrm{mV} / \mathrm{NHE}$ for an air-saturated one. The redox couple provides us with a crucial thermodynamic quantity, $\Delta_{\mathrm{r}} \mathrm{G}_{\mathrm{red} / \mathrm{ox}}^{\text {sol }}$ the (positive) Gibbs energy change (eV/particle) of the oxidation reaction red $\rightarrow$ ox $+e$ in vacuum at rest at infinity. This level, denoted $\mathrm{VL}^{\infty}$, is the thermodynamic reference energy ${ }^{38}$ (see Figure $1(\mathrm{a})$ ). Considering the ferricyanide/ferrocyanide couple (in the so-called Zobell solution ${ }^{39}$ we use) or the $\mathrm{Fe}^{3+}(\mathrm{aq}) / \mathrm{Fe}^{2+}(\mathrm{aq})$ one, for which one electron $e$ is exchanged, the reaction at the electrode is ox $+e$ (metal) $\rightleftarrows$ red. We show in section S1 of the SI that, at equilibrium, a Galvani potential difference appears at the metal/solution interface, such that the electrochemical potentials (i.e. the $F L$ ) are aligned. Then (at constant pressure and temperature):

$\widetilde{\mu}_{\mathrm{e}}^{\mathrm{met}}=\widetilde{\mu}_{\mathrm{red}}^{\mathrm{sol}}-\widetilde{\mu}_{\mathrm{ox}}^{\mathrm{sol}}=-\Delta_{\mathrm{r}} G_{\mathrm{red} / \mathrm{ox}}^{\mathrm{sol}}$

where $\widetilde{\mu}_{\mathrm{e}}^{\mathrm{met}}, \widetilde{\mu}_{\mathrm{red}}^{\mathrm{sol}}$ and $\widetilde{\mu}_{\mathrm{ox}}^{\mathrm{sol}}$ are the electrochemical potentials of the metal electrons, of the reduced, and of the oxidized form of the electroactive species in water, respectively. The electronic diagram after $\mathrm{FL}$ alignment is depicted in Figure 1(a). FL is positioned $-\widetilde{\mu}_{\mathrm{e}}^{\text {met }}$ (or equivalently $\Delta_{\mathrm{r}} \mathrm{G}_{\mathrm{red} / \mathrm{ox}}^{\text {sol }}$ ) below $\mathrm{VL}^{\infty} . \Delta_{\mathrm{r}} \mathrm{G}_{\mathrm{red} / \mathrm{ox}}^{\text {sol }}$ is given by the following equation:

$\Delta_{\mathrm{r}} \mathrm{G}_{\text {red/ox }}^{\text {sol }}=\mathrm{E}_{\mathrm{ox} / \mathrm{red}}+\Delta_{\mathrm{r}} \mathrm{G}_{\mathrm{H}_{2} / \mathrm{H}^{+}}^{\ominus}$

where $\mathrm{E}_{\mathrm{ox} / \mathrm{red}}$ (expressed in $\mathrm{V}$ ) is the reduction potential of the couple expressed with respect to the reference electrode potential, i.e. the standard hydrogen electrode (SHE). $\mathrm{E}_{\mathrm{ox} / \mathrm{red}}$ is measurable by voltammetry or potentiometry. The standard Gibbs energy $\Delta_{\mathrm{r}} \mathrm{G}_{\mathrm{H}_{2} / \mathrm{H}^{+}}^{\ominus}$ of the oxidation reaction $1 / 2$ $\mathrm{H}_{2}(\mathrm{~g})+\mathrm{H}_{2} \mathrm{O}(\mathrm{I}) \rightarrow \mathrm{H}_{3} \mathrm{O}^{+}(\mathrm{aq})+e\left(\right.$ at $\mathrm{VL}^{\infty}$ ) has been calculated with high accuracy by Isse and Gennaro (see $\mathrm{SI}$, section S2). ${ }^{38}$ The value they recommend is $4.281 \mathrm{eV}$. If $\mathrm{VL}^{\mathrm{S}}$ ("just outside the surface) instead of $\mathrm{VL}^{\infty}$ is now considered, one must add the surface dipolar contribution ${ }^{10,40}|\mathrm{q}| \chi^{\mathrm{d}}$ (see Figure $1(\mathrm{a})$ ), which is $+0.14 \mathrm{eV}$, as estimated by Fawcett, ${ }^{41}$ and recently calculated (DFT) by Ambrosio et al.. ${ }^{10}$ One obtains a $\mathrm{VL}^{\mathrm{S}}-\mathrm{FL}$ difference of $4.42 \mathrm{eV}$ for the $\mathrm{H}^{+} / \mathrm{H}_{2}$ couple, a value remarkably close to that recommended by $\operatorname{Trasatti}^{42}(4.44 \mathrm{eV})$ who, in fact, considered $\mathrm{VL}^{\mathrm{S}}$ (and not $\mathrm{VL}^{\infty}$ ) as the vacuum level of reference. Therefore, for the redox couples considered here 
(with one electron exchanged), the calculated work function $\mathrm{q} \Phi^{\text {calc }}\left(\mathrm{VL}^{\mathrm{S}}\right)$ is:

$\mathrm{q} \Phi^{\text {calc }}=\Delta_{\mathrm{r}} \mathrm{G}_{\text {red } / \mathrm{ox}}^{\text {sol }}+|\mathrm{q}| \chi^{\mathrm{d}}$

$\mathrm{q} \Phi^{\text {calc }}$ can be directly compared to the experimental work function given by the cut-off of the SEEDC.

If the question of the electronic level alignment at the solution/metal is now resolved with the addition of a redox couple, the vexing question of the streaming potential remains intact. The question was not addressed in ref. ${ }^{24}$ where the "FL procedure" of $\operatorname{ref}^{17}$ (a static NAP experiment with no streaming potential at stake) was used. Indeed, we shall see that the difference between the measured work function ( $\left.\mathrm{q} \Phi^{\text {meas }}\right)$, and the calculated one $\left(\mathrm{q} \Phi^{\text {calc }}\right)$ gives the streaming potential energy $\mathrm{q} \phi_{\mathrm{str}}$, and therefore the measured BEs can be corrected.

\section{Experimental}

The liquid jet setup system of the soft X-ray PLEIADES beamline of SOLEIL synchrotron facility is described in detail in ref $^{43}$. The scheme given in Figure 1 (b) summarizes all the useful information on the experimental geometry and the electrical connections. The "electrode" is a gold-plated stainless-steel union kept at room temperature and placed upstream of the glass capillary. Downstream of the capillary, we use a system to recover the solution and allow further analyses (see below). This solution-recoverer consists in a beryllium copper alloy catcher that is in electrical contact with the gold-plated electrode. The "upstream electrode" and the "downstream catcher" can be both grounded, or both biased to negative voltages to measure SEEDC curves. Parameters useful for the discussion of results, such as the photon energy $h v$, flowrates are recorded in the text and the figure captions.

The so-called "Zobell" ferricyanide/ferrocyanide solution is a widely used oxidation reduction potential standard. ${ }^{39}$ It consists of $3.33 \mathrm{mM} \mathrm{K}_{4} \mathrm{Fe}(\mathrm{CN})_{6}\left(\mathrm{Fe}^{\prime \prime}\right)$ and $3.33 \mathrm{mM} \mathrm{K}_{3} \mathrm{Fe}(\mathrm{CN})_{6}$ ( $\mathrm{Fe}^{\mathrm{III}}$ ) in a $0.1 \mathrm{M} \mathrm{KCl}$ solution. At the temperature of SOLEIL laboratory, i.e. $21^{\circ} \mathrm{C}$, the open circuit potential (OCP) of the Zobell solution is $0.441 \mathrm{~V}$, referenced to the SHE. Control voltammetry measurements carried out at $22^{\circ} \mathrm{C}$ (see $\mathrm{SI}$, Section S3 Figure S2) for a fresh solution give an OCP SHE of $0.439 \mathrm{~V}$, which is coherent with the known redox potential dependence on temperature. ${ }^{39}$ After exposure to the synchrotron beam the recovered solution presents a voltammogram (see Section S3 of the SI, Figure S2) identical to that of the fresh solution, in particular the limiting currents, which shows that there has been no significant change in the composition of the redox species during synchrotron irradiation. Given the OCP and voltammetry

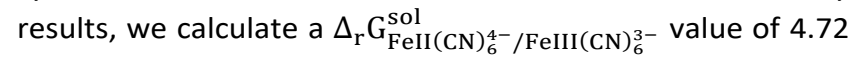
$\mathrm{eV}$ (equation $\{2\})$ and a calculated work function $\mathrm{q} \Phi^{\text {calc }}$ of
$4.86 \mathrm{eV}$ (equation $\{3\}$ ). The $\mathrm{C}$ 1s spectrum shown in the $\mathrm{SI}$, section S4, Figure S3 is void of any component at $285 \mathrm{eV}$ characteristic of organic contamination.

We also considered the $\mathrm{Fe}^{3+}(\mathrm{aq}) / \mathrm{Fe}^{2+}(\mathrm{aq})$ couple, using a $50 \mathrm{mM} \mathrm{FeCl}_{3} / 50 \mathrm{mM} \mathrm{FeCl}_{2}$ solution. As the starting solution was not buffered at very low $\mathrm{pH}$, the experiments were made in the presence of solid oxyhydroxides. ${ }^{44}$ The OCP measured by potentiometry at $22^{\circ} \mathrm{C}$ (see $\mathrm{SI}$ section S3), is stable at 0.720 $\mathrm{V} / \mathrm{SHE}, 10 \mathrm{~min}$ after preparation of the solution. Therefore $\Delta_{\mathrm{r}} \mathrm{G}_{\mathrm{Fe}^{2+} / \mathrm{Fe}^{3+}}^{\text {sol }}=5.00 \mathrm{eV}$ and $\mathrm{q} \Phi^{\text {calc }}$ is $5.14 \mathrm{eV}$.

\section{Results and discussion}

The SEEDC of the pure Zobell solution (hv=91.21 eV) is reported in Figure 2(a) (red dotted curve). The solution was (nominally) biased to $-20.57 \mathrm{~V}$ (see SI section S5). The XPS measured increase in kinetic energies $\mathrm{qV}_{\text {bias }}$ was $20.52 \mathrm{eV}$. The latter value was subtracted to the KE. The SEEDC is plotted on a KE scale that is referenced to the $\mathrm{FL}$ (electrode/analyser), to directly measure the work function. The curve is fitted with an erf step function:

$\mathrm{I}_{\mathrm{SEEDC}}(\mathrm{KE})=\mathrm{H}\left(\frac{1}{2}+\frac{1}{2} \operatorname{erf}\left(1.665 \times \frac{\mathrm{KE}-\mathrm{KE}(\mathrm{MP})}{\Gamma_{\mathrm{SEEDC}}}\right)\right)$

where $\mathrm{H}$ measures the amplitude of the step, KE(MP) determines the KE of the mid-point (MP) and $\Gamma_{\text {SEEDC }}$ describes the broadening of the step (the full width at half maximum of the derivative, which is a Gaussian). To ease comparison with other published data, we will also consider the "onset" of the step defined as the intercept of the tangent at the MP with the horizontal baseline. The kinetic energy difference $\mathrm{KE}(\mathrm{MP})-\mathrm{KE}$ (onset) is determined mathematically using:

$$
\mathrm{KE}(\mathrm{MP})-\mathrm{KE}(\text { onset })=\frac{1}{4} \sqrt{\frac{\pi}{\ln (2)}} \times \Gamma_{\mathrm{SEEDC}}=0.532 \times
$$

$\Gamma_{\text {SEEDC }}$

The fitting parameters are given in Table 1.

For the Zobell solution, we find that $\Gamma_{\text {SEEDC }}$ is $0.58 \mathrm{eV}$. $\Gamma_{\text {SEEDC }}$ is much larger than the value reported by Olivieri et al. ${ }^{24}$ (50 meV) for a $\mathrm{NaCl}$ solution. The large value we find cannot be accounted for by the resolution of the hemispherical analyser that is $\sim 5 \mathrm{meV}$ (the photon bandwidth does not matter for the SEEDC).

We shall see that the SEEDC broadening can be due to the liquid jet experimental setup itself. Let us assume that the jet is positively charged when it goes out into the vacuum (which is indeed the case for the Zobell solution, see below). Then the electric potential will be higher downstream of the capillary than upstream. At PLEIADES, the jet does not break before entering the catcher of the solution-recoverer, and thus the liquid remains in contact with it. Given that a redox couple is introduced in the liquid, the downstream catcher 


\section{(a)}
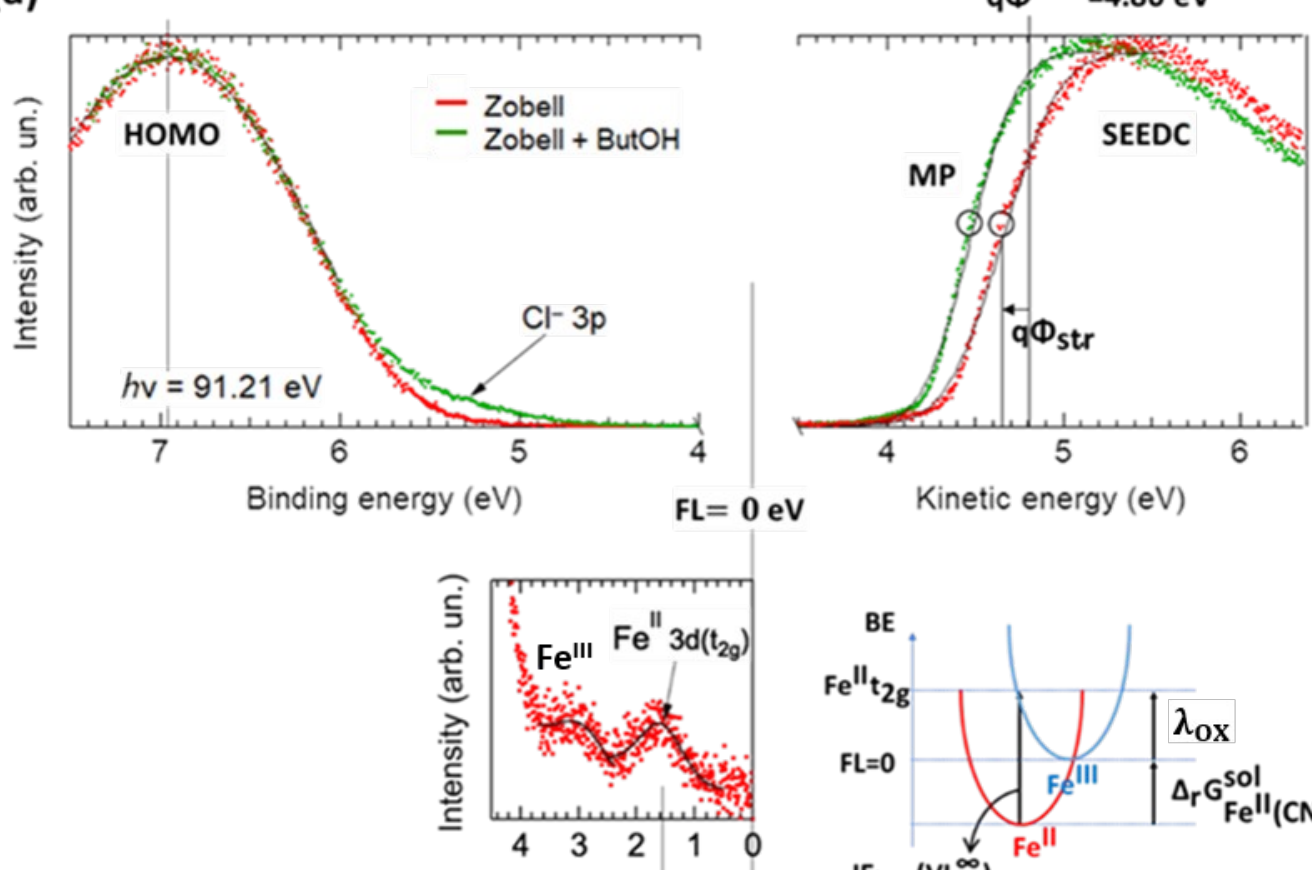

Binding energy (eV)

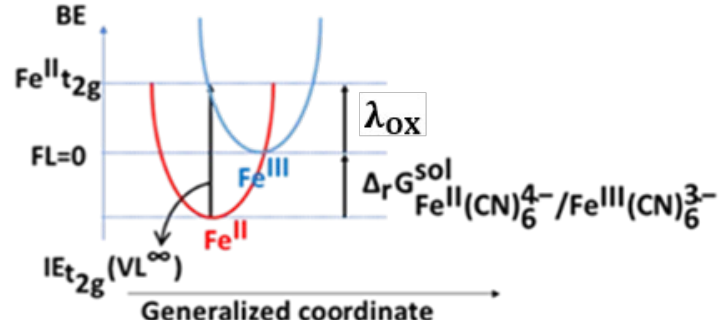

$1.54 \mathrm{eV}$

(b)
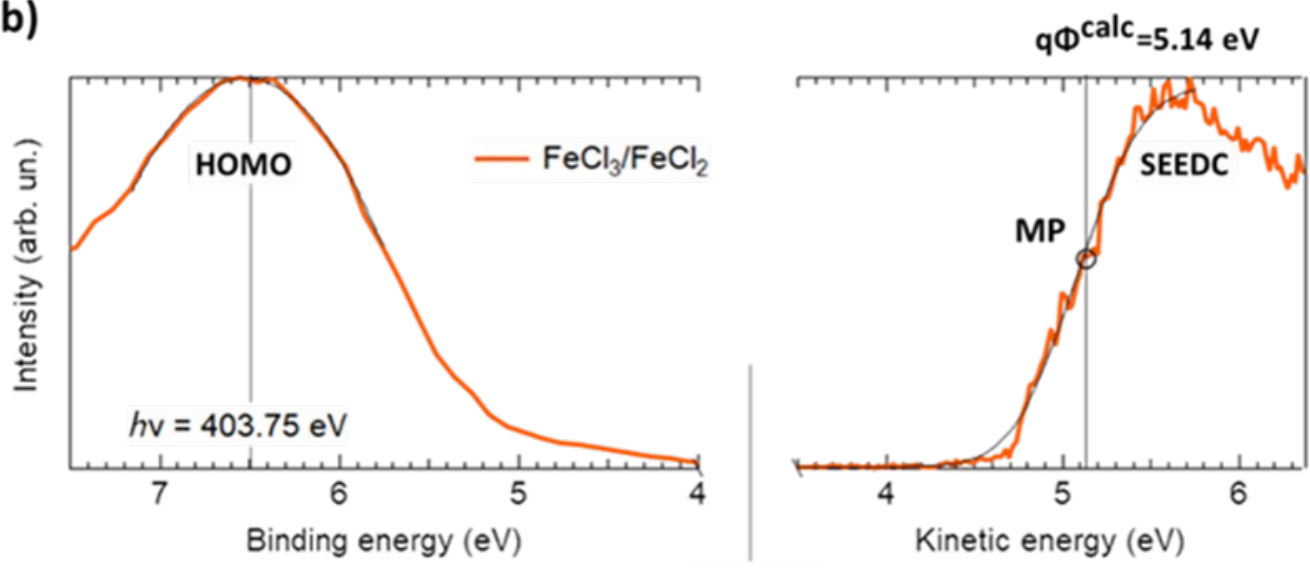

$\mathbf{F L}=0 \mathrm{eV}$

Figure 2. (a) The red dotted curves correspond to the HOMO and SEEDC of the Zobell solution ( $3.33 \mathrm{mM} \mathrm{FeIII(CN})_{6}^{3-}(\mathrm{aq}) / 3.33 \mathrm{mM} \mathrm{FeII}(\mathrm{CN})_{6}^{4-}(\mathrm{aq})$ in $\left.0.1 \mathrm{M} \mathrm{KCl}\right)$. The green dotted curves correspond to the HOMO and SEEDC of the Zobell +ButOH solution, 1-butanol (64 mM) dissolved in the Zobell solution. BE and KE are corrected for $\mathrm{qV}_{\text {bias }}$ (equal to $20.51 \mathrm{eV}$ ) and referenced to FL (analyzer/upstream electrode). The HOMO centroid is indicated by a vertical bar. The SEEDC rising edge is fitted with a dark solid line using equation \{4\}. The mid-point MP, indicated by a small black circle, marks the position of the measured work function $\mathrm{q} \Phi^{\text {meas }}(4.65 \mathrm{eV}$ for the clean solution and $4.48 \mathrm{eV}$ for Zobell + ButOH). The position of $\mathrm{q} \Phi^{\text {calc }}(4.86 \mathrm{eV})$ for the Zobell solution is indicated by a vertical line. $\mathrm{q} \phi_{\text {str }}$ is $-0.21 \mathrm{eV}$ (see text), therefore BE (KE) are overestimated (underestimated) by $+0.21 \mathrm{eV}$. The photon energy $\left(\mathrm{hv}=91.21(02) \mathrm{eV}\right.$ ) and $\mathrm{qV}_{\text {bias }}$ were kept constant while replacing the pristine Zobell solution by the Zobell + ButOH solution. The nozzle diameter is $40 \mu \mathrm{m}$ and the flowrate $2.5 \mathrm{~mL} / \mathrm{min}$. Curve fitting parameters of the HOMO and SEEDC curves are in Table 1. A zoomed view of the band gap is given for the Zobell solution, where the ferricyanide Fe"ll and ferrocyanide Fe"l valence levels show up. The energy level scheme relates the vertical ionization energy of ferrocyanide Fe" (equal to the sum of

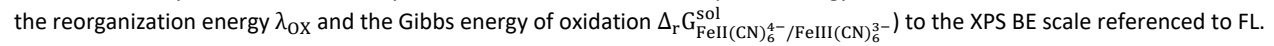

(b) The orange curves correspond to the $\mathrm{HOMO}$ and SEEDC curves of the $50 \mathrm{mM} \mathrm{FeCl} / 50 \mathrm{mM} \mathrm{FeCl} 2$ solution. $\mathrm{BE}$ and $\mathrm{KE}$ are corrected for $\mathrm{qV}_{\text {bias }}(19.97 \mathrm{eV})$ and referenced to $\mathrm{FL}$ (analyzer/upstream electrode). The HOMO centroid is indicated by a vertical bar. The SEEDC rising edge is fitted with a dark solid line using equation \{4\}. The mid-point MP is indicated by a small circle. The position of $\mathrm{q}^{\text {calc }}\left(5.14 \mathrm{eV}\right.$ ), indicated by a vertical line, coincides practically with the MP ( $\mathrm{q} \phi_{\text {str }}$ is negligible) of the SEEDC rising edge at $5.11 \mathrm{eV}$. $\mathrm{hv}$ is equal to $403.75(06) \mathrm{eV}$. The nozzle diameter is $25 \mu \mathrm{m}$, and the flowrate $0.8 \mathrm{~mL} / \mathrm{min}$. Curve fitting parameters of the HOMO and SEEDC curves are in Table 1 
will provide electrons to the solution (reduction of Fe ${ }^{\text {III }}$ ), while the gold-plated union, upstream of the capillary, will recover electrons (oxidation of Fe"). Then a bipolar electronic current will circulate, ${ }^{45,46}$ Thus, in the presence of a bipolar current the classical Helmholtz-Smoluchowski equation is modified (see SI section S6) :

$$
\phi_{\text {str }}=\frac{\frac{\varepsilon \varepsilon_{0} \zeta(\Delta \mathrm{p}) \mathrm{S}}{\eta \mathrm{L}}}{\frac{\mathrm{K}_{\mathrm{L}} \mathrm{S}}{\mathrm{L}}+\frac{1}{\left(\mathrm{G}_{\mathrm{up}}^{-1}+\mathrm{G}_{\text {down }}^{-1}\right)}}
$$

where $\varepsilon$ is the relative dielectric constant of the solution, $\varepsilon_{0}$ the vacuum permittivity, $\zeta$ the zeta potential, $\eta$ the dynamic viscosity of the solution, $\Delta \mathrm{p}$ the pressure difference before and after the capillary, $\mathrm{K}_{\mathrm{L}}$ the bulk solution conductivity (12.9 $\mathrm{mS} / \mathrm{cm}), \mathrm{S}$ the section of the capillary and $\mathrm{L}$ its length, $\mathrm{G}_{\text {up }}$ the transfer conductance at the gold-plated union electrode upstream of the capillary, and $\mathrm{G}_{\text {down }}$ the transfer conductance of the catcher, downstream of the capillary. $G_{\text {up }}$ is likely large and constant with time. However, $\mathrm{G}_{\text {down }}$ is likely much smaller as the jet splashes in the catcher. Therefore:

$\phi_{\mathrm{str}} \approx \frac{\frac{\varepsilon \varepsilon_{0} \zeta(\Delta \mathrm{p}) \mathrm{S}}{\eta \mathrm{L}}}{\frac{\mathrm{K}_{\mathrm{L}} \mathrm{S}}{\mathrm{L}}+\mathrm{G}_{\mathrm{down}}}$

Equation $\left\{6^{\prime}\right\}$ shows how the catcher/jet junction conductance $\mathrm{G}_{\text {down }}$ can determine the streaming potential, if it is much greater than the solution conductance $\frac{\mathrm{K}_{\mathrm{L}} \mathrm{S}}{\mathrm{L}}\left(10^{-7}\right.$ S) in the capillary. However, as the contact between the jet and the metallic catcher fluctuates with time, $\phi_{\text {str }}$ will reflect the fluctuations of $G_{\text {down }}$, varying around an average value. In those conditions, the MP of the SEEDC rising edge in Figure 2(a) marks the position of $\mathrm{VL}^{\mathrm{S}}$ displaced by the average value of the streaming potential, and $\Gamma_{\text {SEEDC }}$ contains the fluctuation on $\mathrm{G}_{\text {down }}$.

Thus, the nature of the junction between the jet and the downstream catcher or trap can impact the streaming potential. Riley et al. ${ }^{47}$ compared the effects of a grounded copper beryllium alloy catcher (as in the present study) and of a cold trap on the streaming potential, using a $30 \mathrm{mM} \mathrm{NaF/}$ $100 \mathrm{mM}$ phenol solution. They observed that the streaming potential is much greater but also much more stable when the grounded catcher is replaced by a cold trap. According to these authors, the instabilities may arise from the solution "not being in constant contact with the grounded catcher tip". Naturally, one should admit the existence of a bipolar current also in their case due to the presence some unknown redox couple in the solution. A cold trap $\left(G_{\text {down }}=0\right)$ should lead to a stable streaming potential. This may explain why Olivieri et al., ${ }^{24}$ who also used a cold trap, found indeed a value of $\Gamma_{\text {SEEDC }}$ one order of magnitude smaller than the present one.

The $q \Phi$ values are reported in Table 1 . For the Zobell solution $\mathrm{q} \Phi^{\text {meas }}$ is $4.34(06) \mathrm{eV}$ considering the onset and 4.65(06) eV considering the MP. Using equation $\{3\}, \mathrm{q} \Phi^{\text {calc }}$ is $4.86 \mathrm{eV}$. This is $0.21(06) \mathrm{eV}$ greater than the measured $\mathrm{q} \Phi(\mathrm{MP})$, and thus the steaming potential energy $\mathrm{q} \phi_{\mathrm{str}}=$ $\mathrm{q} \Phi^{\text {meas }}(\mathrm{MP})-\mathrm{q} \Phi^{\text {calc }}$ is $\sim-0.21 \mathrm{eV}$. The jet is positively

\begin{tabular}{|c|c|c|c|}
\hline Solution & Zobell & $\begin{array}{c}\text { Zobell plus } \\
\text { Butanol }\end{array}$ & $\begin{array}{l}0.05 \mathrm{M} \mathrm{FeCl}_{3} \\
0.05 \mathrm{M} \mathrm{FeCl}_{2}\end{array}$ \\
\hline $\mathrm{q} \Phi^{\text {calc }}=\mathrm{VL}_{\text {calc }}^{\mathrm{S}}-\mathrm{FL}$ & 4.86 & - & 5.14 \\
\hline $\mathrm{q} \Phi^{\text {meas }}(\mathrm{MP})$ & $4.65(06)$ & $4.48(06)$ & $5.11(06)$ \\
\hline Width $\Gamma_{\text {SEEDC }}$ & 0.58 & 0.49 & 0.73 \\
\hline $\mathrm{q} \Phi^{\text {meas }}$ (onset) & $4.34(06)$ & $4.22(06)$ & $4.72(06)$ \\
\hline $\begin{array}{r}q \phi_{\text {str }} \\
=q \Phi^{\text {meas }}(M P) \\
-q \Phi^{\text {calc }}\end{array}$ & $-0.21(06)$ & - & $-0.03(06)$ \\
\hline $\mathrm{BE}_{\mathrm{FeII}}^{\text {meas }}$ me $_{2}\left(\lambda_{\mathrm{OX}}\right)$ & 1.54 & - & \\
\hline $\begin{array}{c}\mathrm{BE}_{\mathrm{FFIII}}^{\text {corr }} \mathrm{t}_{2 \mathrm{~g}} \\
\text { (corrected } \lambda_{\mathrm{OX}} \text { ) }\end{array}$ & 1.33 & - & \\
\hline $\mathrm{BE}_{1 \mathrm{~b}_{1}(\mathrm{l})}^{\text {meas }}$ centroid & $6.90(06)$ & $6.89(06)$ & $6.48(10)$ \\
\hline $\begin{array}{l}\mathrm{BE}_{1 \mathrm{~b}_{1}(\mathrm{l})}^{\text {corr }} \text { centroid } \\
\left(\mathrm{q} \phi_{\text {str }} \text { corrected) }\right.\end{array}$ & 6.69 & - & 6.44 \\
\hline$\Gamma_{\text {HOMO }}$ & 1.39 & 1.39 & 1.48 \\
\hline $\begin{array}{c}\mathrm{BE}_{1 \mathrm{~b}_{1}(\mathrm{l})}^{\text {meas }} \text { edge } \\
\text { (measured) }\end{array}$ & 5.61 & 5.61 & 5.11 \\
\hline $\begin{array}{c}\mathrm{IE}_{1 \mathrm{~b}_{1}(\mathrm{I})} 1 \mathrm{~b}_{1} \text { centroid to } \\
\text { SEEDC MP }\end{array}$ & $11.55(04)$ & $11.37(04)$ & $11.59(10)$ \\
\hline $\begin{array}{c}\mathrm{IE}_{1 \mathrm{~b}_{1}(\mathrm{l})} 1 \mathrm{~b}_{1} \text { centroid to } \\
\text { SEEDC onset }\end{array}$ & $11.24(04)$ & $11.11(04)$ & $11.20(10)$ \\
\hline
\end{tabular}

Table 1. Work functions, SEEDC widths $\left(\boldsymbol{\Gamma}_{\text {SEEDC }}\right)$, streaming potential energy, ferrocyanide $t_{2 g} B E$ (reorganization energy $\lambda_{\mathbf{O X}}$ ) measured $\left(\mathbf{B E}_{\mathrm{Felli}}^{\text {meas }}{ }_{2 \mathrm{~g}}\right.$ ) and corrected $\left(\mathbf{B E}_{\mathrm{Fell}}^{\text {corr }}{ }_{2 \mathrm{~g}}\right.$ ) for the streaming potential (eq. \{9\}), liquid water HOMO $1 \mathrm{~b}_{1} \mathrm{BE}$, as measured $\left(\mathbf{B E}_{\mathbf{1} \mathbf{b}_{\mathbf{1}}(\mathrm{l})}^{\text {meas }}\right)$ and corrected $\left(\mathbf{B E}_{\mathbf{1}}\right.$ corr $(\mathbf{l})$ for the streaming potential, HOMO widths $\left(\boldsymbol{\Gamma}_{\mathbf{H O M O}}\right)$, ionization energies $\left(\mathbf{I E}_{\mathbf{1 b}_{\mathbf{1}}(\mathrm{I})}\right)$. The accuracy of the measurements is discussed in the SI. The onset of the SEEDC and the edge of the HOMO and are calculated with equations $\{5\}$ and $\{7\}$, respectively. All quantities are given in $\mathrm{eV}$.

charged, which makes that the measured kinetic energies (binding energies) are underestimated (overestimated).

The modified Helmholtz-Smoluchowski equation (Equation $\{6\}$ ) shows that $\phi_{\text {str }}$ depends on the chemistry of the solution via $\zeta, \Delta p$ (flowrate), and on a multiplicity of other experimental parameters, such as the bipolar current conductances. To illustrate this point, we present in Figure 2(b), see the solid orange curves, the HOMO (measured at $\mathrm{hv}=403.75(06) \mathrm{eV}$ ) and the SEEDC of a $0.05 \mathrm{M} \mathrm{FeCl}_{3} / 0.05 \mathrm{M}$ $\mathrm{FeCl}_{2}$ solution. The $\mathrm{BE}$ (valence) and $\mathrm{KE}$ (SEEDC) are referenced to $\mathrm{FL}$ (electrode/analyser). The fitting parameters are reported in Table 1. $\mathrm{q} \Phi^{\text {meas }}(\mathrm{MP})$ is found equal to $5.11(06) \mathrm{eV}$, which is equal, within the error bars, to the theoretical position $\mathrm{q} \Phi^{\text {calc }}, 5.14 \mathrm{eV}\left(\mathrm{q} \phi_{\mathrm{str}}\right.$ is $\left.-0.04(06) \mathrm{eV}\right)$. Thus, the magnitude of the streaming potential is much smaller than for the Zobell solution. There can be two reasons for a sizeable reduction of the streaming potential. First, $\mathrm{G}_{\text {down }}$ can be larger than in the case of the Zobell solution, due to a better solution/metal contact in the catcher. Second, the chemistry at the glass capillary/solution interface is likely different. In fact, the zeta potential $\zeta$ of the glass capillary depends on the $\mathrm{pH}$. For amorphous silica grown on a Si wafer, ranges from $-66 \mathrm{mV}$ at $\mathrm{pH}=9$ to $+13 \mathrm{mV}$ at $\mathrm{pH}=2$, with the isoelectric point at $\mathrm{pH} 3.8 .{ }^{48}$ Indeed, the $\mathrm{FeCl}_{3} / \mathrm{FeCl}_{2}$ solution is acidic $\left(\mathrm{pH}=1.94\right.$, as given by PHREEQC, ${ }^{49}$ see $\left.\mathrm{SI}\right)$, while the Zobell solution is nominally at $\mathrm{pH}=7$. The glass surface should be positively charged for the $\mathrm{FeCl}_{3} / \mathrm{FeCl}_{2}$ solution and negatively charged for the Zobell one.

Binding energies are measured while the solution is negatively biased (the bias has no effect on the liquid phase $\mathrm{HOMO}$ as the gas phase $1 \mathrm{~b}_{1}$ is at lower kinetic energy, see $\mathrm{SI}$ ). The binding energy $\mathrm{BE}_{1 \mathrm{~b}_{1}(\mathrm{l})}$ is determined using either the 
centroid of the HOMO ("centroid") fitted by a Gaussian of FWHM $\Gamma_{\text {номо }}$ or the intersection of a horizontal baseline with the tangent to the inflection point of the rising edge ("edge"), in which case:

$$
\mathrm{BE}(\text { centroid })-\mathrm{BE}(\text { edge })=\frac{\Gamma_{\text {номо }}}{\sqrt{2 \ln (2)}}=0.849 \times \Gamma_{\text {Номо }}
$$

We find that the $\mathrm{BE}_{1 \mathrm{~b} 1 \text { (l) }}$ of the Zobell solution (Figure $2(a))$ is $6.90 \mathrm{eV}$ at the $1 \mathrm{~b}_{1} \mathrm{HOMO}$ centroid and $5.61 \mathrm{eV}$ at the edge (see Table 1). Thus the $\mathrm{BE}_{1 \mathrm{~b}_{1}(\mathrm{l})}$ values corrected for the streaming potential are $6.69 \mathrm{eV}$ (centroid) and $5.40 \mathrm{eV}$ (edge). In the gap of water, see the zoomed region in Figure 2(a), we can see two small photoemission peaks. The structures whose centroids are at BEs of $3.0 \mathrm{eV}$ and $1.54 \mathrm{eV}$ are attributed to the valence-ionized ferricyanide and ferrocyanide $t_{2 g}$ states, ${ }^{50}$ respectively. The photoemission process affecting the ferrocyanide $t_{2 g}$ level corresponds to the "vertical" oxidation of ferrocyanide into ferricyanide. The vertical ionization energy is $\mathrm{IE}_{t_{2 \mathrm{~g}}}$ when referenced to $\mathrm{VL}^{\mathrm{S}}$ and $I_{t_{2 g}}-|q| \chi^{d}$ when referenced to $V L^{\infty}$. Because the photoemission process occurs at a timescale much shorter than the motion of nuclei (molecular vibrations of the ion, and rotation of the surrounding water molecules), the final unrelaxed state of ferrocyanide has an ionization energy referenced to $\mathrm{VL}^{\infty}$ greater than the Gibbs energy difference

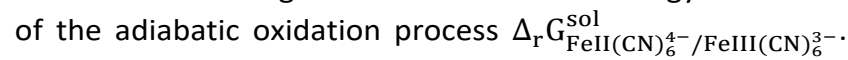
As shown in the energy level diagram of Figure 2(a), the reorganization free energy of the oxidized species $\lambda_{\mathrm{OX}}$ of the redox couple is:

$\lambda_{\mathrm{OX}}=\mathrm{BE}_{\mathrm{FeII}} \mathrm{t}_{2 \mathrm{~g}}$ (referenced to $\left.\mathrm{FL}\right)$

or equivalently:

$\lambda_{\mathrm{OX}}=\mathrm{IE}_{\mathrm{FeII}} \mathrm{t}_{2 \mathrm{~g}}-|\mathrm{q}| \chi^{\mathrm{d}}-\Delta_{\mathrm{r}} \mathrm{G}_{\mathrm{FeII}(\mathrm{CN})_{6}^{4-} / \mathrm{FeII}(\mathrm{CN})_{6}^{3-}}$

The valence band spectrum (referenced to $\mathrm{FL}$ of the analyser/downstream electrode) in Figure 2(a) indicates that the measured binding energy of ferrocyanide $\mathrm{BE}_{\mathrm{FeII}}^{\text {meas }} \mathrm{t}_{2 \mathrm{~g}}$ is $1.54 \mathrm{eV}$. From equation $\{8\}, \lambda_{\mathrm{OX}}$ is equal to the experimental $B E$ value in the absence of streaming potential. This binding energy value is overestimated, due to the streaming potential (by $-0.21 \mathrm{eV}$, see above). After correction, $\lambda_{\mathrm{OX}}\left(=\mathrm{BE}_{\text {FeII }_{2 \mathrm{~g}}}^{\text {corr }}\right)$ is $1.33 \mathrm{eV}$. This is equivalent to using equation $\{9\}$, with $\mathrm{IE}_{\mathrm{FeII}} \mathrm{t}_{2 \mathrm{~g}}=6.19 \mathrm{eV}\left(\mathrm{VL}^{\mathrm{S}}\right.$ is determined by the mid-point of the SEEDC).

In the absence of a well-defined ferricyanide/ferrocyanide redox couple, the determination of $\lambda_{\mathrm{OX}}$ is normally impracticable, because the electronic levels of water, and in particular the binding energy of the ferrocyanide solute, can be fixed by some unknown "background" couple (see ref $^{37}$ ). Nonetheless, considering a solution with the ferrocyanide ion alone, Seidel et al. have calculated a $\lambda_{\text {OX }}$ value of $1.47 \mathrm{eV} .^{50}$ This $\lambda_{\text {ox }}$ value is only 0.14 $\mathrm{eV}$ higher than that of $1.33 \mathrm{eV}$ we find with equation $\{9\}$. The relatively good agreement can be explained because the dipolar energy contribution $|q| \chi^{d}$, not considered by Seidel et al., is small $(0.14 \mathrm{eV})$, and because $\mathrm{IE}_{\mathrm{Fe} \text { II } \mathrm{t}_{2 \mathrm{~g}}}(6.11 \mathrm{eV})$ and the standard Gibbs oxidation energy of the ferricyanide/ferrocyanide

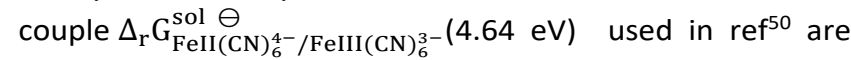
close to the present $\mathrm{IE}_{\mathrm{Fe} \text { II t }}$ (6.19 $\left.\mathrm{eV}\right)$ and $\Delta_{\mathrm{r}} \mathrm{G}_{\mathrm{FeII}(\mathrm{CN})_{6}^{4-} / \mathrm{FeIII}(\mathrm{CN})_{6}^{3-}}^{\text {sol }}(4.72 \mathrm{eV})$.

The present experiment provides $\lambda_{\text {OX }}$ values in the 1.33 $\mathrm{eV}$ (corrected from streaming potential)-1.54 eV (uncorrected). The corrected $\lambda_{\mathrm{OX}}$ value is within $0.1 \mathrm{eV}$ of those calculated by DFT (1.23-1.24 eV $\left.\mathrm{eV}^{50,51}\right)$. However, experimental $\lambda_{\mathrm{OX}}$ from electrochemical current-potential characteristics are distinctly smaller: they span from $0.4 \mathrm{eV}^{52}$ to $0.97 \mathrm{eV} .{ }^{53}$ The reason of the discrepancy with the present XPS study may lie in the fact that the electrochemical determinations are indirect, depending on the currentpotential theoretical models. ${ }^{52,54}$ Another reason may be that the reorganization energy we measure concerns the bulk liquid phase, while electrochemical measurements depend on the reorganisation energy in the layers close to an electrode. It has been shown recently that the outer-shell reorganization energy can be considerably smaller than that expected for a homogeneous reaction for an electron transfer occurring in the vicinity of a surface electrode. ${ }^{55}$

The ionization energy of the liquid phase $1 b_{1}$ HOMO $\mathrm{IE}_{1 \mathrm{~b}_{1}(\mathrm{l})}$ is the sum of $\mathrm{q} \Phi$ and $\mathrm{BE}_{1 \mathrm{~b} 1(\mathrm{l})}$. However, to obtain it accurately we directly calculate the difference between the KE energy of the SEEDC cut-off and that of liquid water HOMO. In this case, the precision on $\mathrm{IE}_{1 \mathrm{~b}_{1}(\mathrm{l})}$ is better than that for the HOMO BE and the work function separately, because it is essentially determined by the precision on $h v$. Moreover, being a difference in KE, it is not affected by the residual streaming potential. $\mathrm{IE}_{1 \mathrm{~b}_{1}(\mathrm{l})}$ depends on the choice of the HOMO BE (centroid or edge) and work function cutoff (onset or MP). Within the Frank Condon approximation, the HOMO centroid marks the vertical ionization (the nuclei coordinates in the ionized state are still those of the ground state). It is not completely clear if the HOMO edge in Figure 2(a) positions the adiabatic ionization energy, as Perry et al. claim. ${ }^{31}$ To discuss this point we consider calculations ${ }^{56}$ of ionization energies of the water hexamer, that can be considered as an approximant of bulk liquid water. The ionized $\left[\left(\mathrm{H}_{2} \mathrm{O}\right)_{6}^{+}\right]$species evolves towards $\left(\mathrm{H}_{2} \mathrm{O}\right)_{5} \mathrm{H}^{+}+\mathrm{OH}$ via proton transfer from the ionized molecule. The energy difference between the vertical IE and the adiabatic one is $\sim 2.5 \mathrm{eV}$, a value significantly greater than the energy difference of $1.2 \mathrm{eV}$ (equation \{7\}) between the centroid and the extrapolated edge. Thus, as the physical interpretation $\mathrm{BE}$ of the HOMO edge is not completely clear, we consider only the HOMO centroid. For the Zobell solution, $\mathrm{IE}_{1 \mathrm{~b} 1(\mathrm{l})}$ is equal to $11.24(04) \mathrm{eV}$ (see Table 1 ) considering the SEEDC onset and $11.55(04) \mathrm{eV}$ considering the MP. For its part, the $\mathrm{IE}_{1 \mathrm{~b} 1(\mathrm{l})}$ (MP) of the $\mathrm{FeCl}_{3} / \mathrm{FeCl}_{2}$ solution is $11.59(06) \mathrm{eV}$ (at MP), equal within the error bars, to that of the Zobell solution. As expected, $\mathrm{IE}_{1 \mathrm{~b}_{1}(\mathrm{l})}$ is independent of $\mathrm{FL}$, and thus of the redox couples present in the solution.

Therefore, comparisons can also be made with the $\mathrm{IE}_{1 \mathrm{~b}_{1}(\mathrm{l})}$ values of solutions that do not incorporate any known redox potential. The HOMO and SEEDC spectra of the plain 
$0.1 \mathrm{M} \mathrm{KCl}$ solution are shown in section S7, Figure S5 of the SI. The $\mathrm{IE}_{1 \mathrm{~b}_{1}(\mathrm{l})}$ is $11.34(04) \mathrm{eV}$ considering the SEEDC onset and $11.58(04)$ eV considering the SEEDC MP. The latter value falls into the error bars of the value obtained for the Zobell solution and of the $\mathrm{FeCl}_{3} / \mathrm{FeCl}_{2}$ solution.

Previous measurements concerning solutions without electroactive species were based on the gas phase $1 b_{1}$ reference method. The values that Winter et al. ${ }^{13}$ obtained in 2004 (11.16 eV) and Kurahashi et al. ${ }^{25}$ in 2014 (11.31(04) eV) were likely affected by the contribution of the CPD/streaming potential on the gas phase $1 b_{1}$ energy position. The most recent published value of $\mathrm{IE}_{1 \mathrm{~b}_{1}(\mathrm{l})}(2020)$ is provided by Perry et al.. ${ }^{31}$ Perry et al. have used the $1 b_{1}$ gas phase method in combination with a CPD/streaming potential elimination procedure. The method is critically reviewed by Nishitani et al. ${ }^{26}$ who consider that the calibration is correct to $0.1 \mathrm{eV}$. Perry et al. have found that $\mathrm{IE}_{1 \mathrm{~b}_{1}(\mathrm{l})}$ is $11.67(15) \mathrm{eV}$ for a $\mathrm{NaCl}$ solution $(10 \mathrm{mM}$ to $500 \mathrm{mM})$. This latter value enters the error bars of $I_{1 \mathrm{~b} 1(\mathrm{l})}$ we have determined considering the SEEDC MP. Therefore, the "flat vacuum level" method used by Perry et al. would determine in fact the average value of $\mathrm{VL}^{\mathrm{S}}$, if one admits that the streaming potential fluctuates.

The hypothesis that the SEEDC MP (and not the onset) corresponds to $\mathrm{VL}^{\mathrm{S}}$ in liquid jet experiments affected by streaming potential fluctuations may find a further confirmation from new data obtained from another liquid jet XPS setup. At the time of writing the present paper, Bernd Winter communicated us (yet unpublished) $\mathrm{IE}_{1 \mathrm{~b}_{1}(\mathrm{l})}$ values of water. ${ }^{57}$ There was no added redox couple in the alkali halide solutions examined by these authors, therefore only $\mathrm{IE}_{1 \mathrm{~b}_{1}(\mathrm{l})}$ values can be compared with our data. The Winter group uses the SEEDC method, as in ref ${ }^{17}$ and the present work. Judging from the SEEDC curves shown in Figure 5 of ref $^{57}$, the step width $\Gamma_{\text {SEEDC }}$ is $\sim 0.47 \mathrm{eV}$ using equation $\{5\}$ and considering an onset-MP energy difference of $\sim 250 \mathrm{meV}$. This $\Gamma_{\text {SEEDC }}$ value is comparable to the ones we give in Table 1 , and thus the broadening may have the same origin. Taking the SEEDC step shape into consideration, the found ionization energies are also in excellent agreement, despite the use of different XPS setups. Considering the SEEDC onset, the Winter group finds an $I_{1 b_{1}(l)}$ of $11.33(03) \mathrm{eV}$, close to the value we find 11.24(04) eV for the Zobell solution (Table 1). If the SEEDC MP is taken as a reference, we deduce that $\mathrm{IE}_{1 \mathrm{~b}_{1}(\mathrm{l})}$ is $11.58 \mathrm{eV}$, which falls within the error bars of our findings (Table 1 ).

Now we explore the effect of the addition of a polar organic molecule 1-butanol (with a concentration $64 \mathrm{mM}$ ) on the work function and vertical ionization energy of the Zobell solution. The corresponding valence band and SEEDC are shown as green dotted curves in Figure 2(a). The corresponding $C 1$ s spectrum is shown in section S4 of the SI. Figure 2(a) shows that the centroid of the liquid phase $1 b_{1}$ peak is found at the same position as that of the pristine Zobell solution. In fact, the FL position in the band gap is not affected by the addition of the alcohol. The voltammogram presented in Figure S2, section S3 of the SI shows indeed no change in the OCP with respect to that of the Zobell solution. However we see in the valence band spectrum an increase in the photoemission intensity at a $\mathrm{BE}$ of $\sim 5 \mathrm{eV}$, which we attribute to the $\mathrm{Cl} 3 p$ level of $\mathrm{Cl}^{-}$ions ${ }^{17}$ segregated in layers close to the surface, due to the presence of the surfactant. While the $\mathrm{FL}$ remains at the same position, the MPreferenced workfunction $\mathrm{q} \Phi$ meas changes appreciably from $4.65 \mathrm{eV}$ to $4.48 \mathrm{eV}$ (Table 1$)$. The $-0.17 \mathrm{eV}$ variation is attributed to a change in the surface dipolar energy brought by the surfactant. This variation suggests that the dipole moment of the surfactant is oriented outward, with the hydrophobic tail oriented away from the surface, in accord with calculations. ${ }^{58}$ Three decades ago, Dynarowicz, ${ }^{59}$ using the dynamic jet method, ${ }^{60}$ had already observed that the (Volta) electric potential of the surface of water increases $(\Delta \mathrm{V}=+200 \mathrm{meV})$ upon the adsorption of 1-butanol (with a concentration equal to the present one). The positive $\Delta \mathrm{V}$ corresponds in fact to a decrease of the work function by the same magnitude, which is that we observe. This experiment also shows that the "work function method" used to estimate the streaming potential is unapplicable when the water surface is contaminated by organics. If 1-butanol affects the surface dipole energy, it does not alter the "width" of the SEEDC rising edge, as $\Gamma_{\text {SEEDC }}(0.49 \mathrm{eV})$ is practically equal to that of the pristine Zobell solution. Therefore, surface contamination by organics does not lead to an increase of $\Gamma_{\text {SEEDC }}$ as it was proposed in ref $^{24}$. The changes in the surface dipole energy due to the 1-butanol surfactant are less impressive than the decrease in the work function measured by Olivieri et al. ${ }^{24}$ when butylamine $(0.15 \mathrm{M})$ is added to a $0.05 \mathrm{M} \mathrm{NaCl}$ solution, that is $-0.53 \mathrm{eV}$ with respect to the plain $\mathrm{NaCl}$ solution. This considerable change in the work function may not be entirely due to a change in the surface dipole, as suggested in ref ${ }^{24}$. Indeed, as the butylamine $\mathrm{pK}_{\mathrm{b}}$ is 3.2 , the $\mathrm{pH}$ of the solution is 11.97 at the considered concentration. Considering that the $\mathrm{pH}$ of the pristine $\mathrm{NaCl}$ solution is around 7 (the solution is under constant He purge to avoid $\mathrm{CO}_{2}$ dissolution ${ }^{24}$ ), the change is $+5 \mathrm{pH}$ units. If we assume that the "background redox couple" ${ }^{37}$ depends on the $\mathrm{H}^{+}$concentration, such as the oxygen reduction reaction, or the proton reduction reaction, this may result in a decrease in the "background redox potential" by $-0.059 \times$ $5=-0.3 \mathrm{~V}$. As $\mathrm{VL}^{\infty}-\mathrm{FL}$ will be reduced by the same amount in $\mathrm{eV}$, there are $-0.2 \mathrm{eV}$ left for the butylamine dipolar contribution, which is comparable to what we have found for 1-butanol. The present reanalysis of the data of ref. ${ }^{24}$ emphasizes the importance of controlling the position of the FL with a known redox couple.

Finally, the introduction of a redox couple in the solution also suggests further improvements that could be brought to liquid jet designs dedicated to photoemission spectroscopy. Having in mind the electrical scheme of Figure 1(b), the bipolar current circulating between the upstream electrode and the downstream catcher will be efficient to reduce or even suppress the streaming potential, only when the liquid/metal contact in the catcher will have a large, stable conductance. This could be realized using clean metallic inner parts forming a reservoir inside the catcher. Alternately to that scheme, the glass capillary could be replaced by a metallic one. Then the capillary itself would provide the circuit for the bipolar current created at its entrance and exit. Bipolar faradaic depolarization, as expected from the microfluidic studies of Duval et al., ${ }^{46}$ would lead to a sizeable reduction of the streaming potential. 


\section{Conclusion}

Liquid jet setups are now the "standard" water sample environment in XPS experiments because of its many advantages such as surface cleanliness, minimized radiolytic effects, and versatility. In this context, referencing properly the electronic energies of liquid water in jets is crucial for the advancement of the XPS of aqueous solutions. Starting from thermodynamic considerations, we have considered the referencing of energies with respect to the Fermi level common to the XPS analyser and an electrode in contact with a solution containing a redox couple with a known "electrode potential". This appears as a natural alternative to referencing the energies with respect to the vacuum level "just outside the surface", obtained from the ionization energies of the gas phase molecules surrounding the jet.

As the "Fermi level" methodology involves the measurement of the work function via the secondary electron energy distribution curve, the shape of the rising edge was discussed with respect to the electrical diagram of the liquid jet setup, and the energy position analysed with respect to electrokinetic effects inherent to liquid jets using glass capillaries. The presence of a known redox couple is a requisite to define properly binding energies and work functions. It also permits to estimate the streaming potential energy, as the difference between measured and calculated work functions, provided that the water surface is clean. The worth of binding energies referenced to the Fermi level has been emphasized in this paper, such as the measurement of the reorganization energy after oxidation of ferrocyanide into ferricyanide $(1.33 \mathrm{eV})$. Even when redox couples are not introduced in aqueous solution, we have shown that the vertical ionization of water (11.55 eV) can be equally determined once it is referenced to the vacuum level "just outside the surface". Finally, the introduction of a redox couple has also suggested further improvements to the actual liquid jet design, aiming at reducing or even suppressing the streaming potential contribution.

\section{Author Contributions}

The manuscript was written through contributions of all authors. All authors have given approval to the final version of the manuscript.

\section{Conflicts of interest}

There are no conflicts to declare.

\section{Acknowledgements}

LPR thanks the Ecole Doctorale ED388 and Sorbonne Université for her PhD grant. AB thanks Région lle de France for his PhD grant "HORS DIM EAU". Some of the experiments were carried out with the approval of synchrotron SOLEIL (proposals numbers 20161035 and 20181857). We thank the technical service personnel of the SOLEIL chemistry laboratories for their helpful support.

\section{Notes and references}

1

2

3

4

5

6

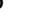

A. Bernas, C. Ferradini and J.-P. Jay-Gerin, Chem. Phys., 1997, 222, 151-160.

J. V. Coe, Int. Rev. Phys. Chem., 2001, 20, 33-58.

J. V. Coe, A. D. Earhart, M. H. Cohen, G. J. Hoffman, H. W. Sarkas and K. H. Bowen, J. Chem. Phys., 1997, 107, 6023-6031.

K. Laasonen, M. Sprik, M. Parrinello and R. Car, J. Chem. Phys., 1993, 99, 9080.

T. A. Pham, C. Zhang, E. Schwegler and G. Galli, Phys. Rev. B, 2014, 89, 060202.

C. Adriaanse, J. Cheng, V. Chau, M. Sulpizi, J. VandeVondele and M. Sprik, J. Phys. Chem. Lett., 2012, 3, 3411-3415.

J. Cheng and M. Sprik, Phys. Chem. Chem. Phys., 2012, 14, 11245.

X. Liu, J. Cheng and M. Sprik, J. Phys. Chem. B, 2015, 119, 1152-63.

A. Bouzid and A. Pasquarello, J. Phys. Chem. Lett., 2018, 9, 1880-1884.

F. Ambrosio, Z. Guo and A. Pasquarello, J. Phys. Chem. Lett., 2018, 9, 3212-3216.

F. Ambrosio and A. Pasquarello, Phys. Chem. Chem. Phys., 2018, 20, 30281-30289.

2 A. P. Gaiduk, T. A. Pham, M. Govoni, F. Paesani and G. Galli, Nat. Commun., 2018, 9, 247.

B. Winter, R. Weber, W. Widdra, M. Dittmar, M. Faubel and I. V. Hertel, J. Phys. Chem. A, 2004, 108, 2625-2632. B. Winter and M. Faubel, Chem. Rev., 2006, 106, 1176211.

R. Seidel, S. Thürmer and B. Winter, J. Phys. Chem. Lett., 2011, 2, 633-641.

H. Tissot, G. Olivieri, J.-J. Gallet, F. Bournel, M. G. Silly, F. Sirotti and F. Rochet, J. Phys. Chem. C, 2015, 119, 92539259.

H. Tissot, J.-J. Gallet, F. Bournel, G. Olivieri, M. G. Silly, F. Sirotti, A. Boucly and F. Rochet, Top. Catal., 2016, 59, 605-620.

M. A. Brown, I. Jordan, A. Beloqui Redondo, A. Kleibert, H. J. Wörner and J. A. van Bokhoven, Surf. Sci., 2013, 610, 1-6.

H. Ali, R. Seidel, M. N. Pohl and B. Winter, Chem. Sci., 2018, 9, 4511-4523.

H. Ali, R. Seidel, A. Bergmann and B. Winter, J. Mater. Chem. A, , DOI:10.1039/C8TA09414D.

1 A. L. Linsebigler, G. Lu and J. T. Yates, Chem. Rev., 1995, 95, 735-758.

Z. Guo, F. Ambrosio and A. Pasquarello, ACS Catal., 2020, 10, 13186-13195.

M. D. Scanlon, P. Peljo, M. A. Méndez, E. Smirnov and H. H. Girault, Chem. Sci., 2015, 6, 2705-2720.

G. Olivieri, A. Goel, A. Kleibert, D. Cvetko and M. A. Brown, Phys. Chem. Chem. Phys., 2016, 18, 2950629515.

N. Kurahashi, S. Karashima, Y. Tang, T. Horio, B. Abulimiti, Y.-I. Suzuki, Y. Ogi, M. Oura and T. Suzuki, J. 
Chem. Phys., 2014, 140, 174506.

J. Nishitani, S. Karashima, C. W. West and T. Suzuki, J. Chem. Phys., 2020, 152, 144503.

H. Siegbahn, M. Lundholm, M. Arbman and S. Holmberg, Phys. Scr., 1983, 27, 241-244.

H. Morgner, J. Oberbrodhage, K. Richter and K. Roth, J. Electron Spectros. Relat. Phenomena, 1991, 57, 61-77. A. V. Delgado, F. González-Caballero, R. J. Hunter, L. K. Koopal and J. Lyklema, Pure Appl. Chem., 2005, 77, 1753-1805.

N. Preissler, F. Buchner, T. Schultz and A. Lübcke, J. Phys. Chem. B, 2013, 117, 2422-8.

C. F. Perry, P. Zhang, F. B. Nunes, I. Jordan, A. von Conta and H. J. Wörner, J. Phys. Chem. Lett., 2020, 11, 17891794.

W. F. Egelhoff, Surf. Sci. Rep., 1987, 6, 253-415.

R. A. Marcus, J. Chem. Phys., 1965, 43, 679-701.

E. Laborda, M. C. Henstridge, C. Batchelor-McAuley and

R. G. Compton, Chem. Soc. Rev., 2013, 42, 4894.

H. Gerischer, Appl. Phys. Lett., 1983, 43, 393.

H. Reiss, J. Phys. Chem., 1985, 89, 3783-3791.

S. J. Percival and A. J. Bard, Anal. Chem., 2017, 89, 98439849.

A. A. Isse and A. Gennaro, J. Phys. Chem. B, 2010, 114, 7894-7899.

D. K. Nordstrom, Geochim. Cosmochim. Acta, 1977, 41, 1835-1841.

S. M. Kathmann, I.-F. W. Kuo, C. J. Mundy and G. K. Schenter, J. Phys. Chem. B, 2011, 115, 4369-4377.

W. R. Fawcett, Langmuir, 2008, 24, 9868-9875.

S. Trasatti, Pure Appl. Chem., 1986, 58, 955-966.

S. Malerz, F. Trinter, U. Hergenhahn, A. Ghrist, H. Ali, C. Nicolas, C.-M. Saak, C. Richter, S. Hartweg, L. Nahon, C. Lee, C. Goy, D. M. Neumark, G. Meijer, I. Wilkinson, B. Winter and S. Thürmer, Phys. Chem. Chem. Phys., 2021, 23, 8246-8260.

T. J. Grundl and D. L. Macalady, J. Contam. Hydrol., 1989, 5, 97-117.

J. F. L. Duval, G. K. Huijs, W. F. Threels, J. Lyklema and H. P. van Leeuwen, J. Colloid Interface Sci., 2003, 260, 95106.

J. F. L. Duval and H. P. van Leeuwen, Adv. Colloid Interface Sci., 2020, 275, 102074.

J. W. Riley, B. Wang, M. A. Parkes and H. H. Fielding, Rev. Sci. Instrum., 2019, 90, 083104.

O. Plohl, L. F. Zemljič, S. Potrč and T. Luxbacher, RSC Adv., 2020, 10, 6777-6789.

PHREEQC Version 3, https://www.usgs.gov/software/phreeqc-version-3, (accessed 31 December 2020).

R. Seidel, S. Thürmer, J. Moens, P. Geerlings, J.

Blumberger and B. Winter, J. Phys. Chem. B, 2011, 115, 11671-7.

M. Rubešová, V. Jurásková and P. Slavíček, J. Comput. Chem., 2017, 38, 427-437.

\section{R. Memming and F. Möllers, Berichte der}

Bunsengesellschaft für Phys. Chemie, 1972, 76, 475-481. K. W. Frese, J. Phys. Chem., 1981, 85, 3911-3916.

K. Okada, K. Ueda, T. Tokushima, Y. Senba, H. Yoshida, Y. Shimizu, M. Simon, H. Chiba, H. Okumura, Y. Tamenori,

H. Ohashi, N. Saito, S. Nagaoka, I. . Suzuki, E. Ishiguro, I. Koyano, T. Ibuki and A. Hiraya, Chem. Phys. Lett., 2000, 326, 314-320.

55

R. E. Bangle, J. Schneider, E. J. Piechota, L. TroianGautier and G. J. Meyer, J. Am. Chem. Soc., 2020, 142, 674-679.

Chem. Phys., 2012, 136, 244306.

D. Roca-Sanjuán, J. S. Thürmer, S. Malerz, F. Trinter, U. Hergenhahn, C. Lee, D. M. Neumark, G. Meijer, B. Winter and I. Wilkinson. Retrieved from http://arxiv.org/abs/2104.01630. B. Chen, J. I. Siepmann and M. L. Klein, J. Am. Chem. Soc., 2002, 124, 12232-12237.

P. Dynarowicz, Colloids and Surfaces, 1989, 42, 39-48. M. Paluch and P. Dynarowicz, J. Colloid Interface Sci., 1984, 98, 131-137. 